\title{
Rare earth elements as process indicators for metal and metaloid contaminated groundwater
}

\author{
Joe DeAN ${ }^{1 *}$, Pallavee SRIVASTAVA ${ }^{1}$, ANDREW \\ MITCHELL $^{1}$, BILL PERKINS ${ }^{1}$ \\ ${ }^{1}$ Department of Geography and Earth Science, Aberystwyth \\ University, Aberystwyth, UK, SY23 3DB \\ (*correspondence: jhd10@aber.ac.uk)
}

Diffuse sources of polluted groundwater from contaminated industrial sites account for $21 \%$ of surface water bodies that fail to achieve a 'good quality' status in the Tawe catchment, South Wales, UK. This study has used the rare earth elements (REE) as a hydrogeological tracer at one such site, with the aim of characterising the origin and transport of elements including $\mathrm{Ni}, \mathrm{Cu}, \mathrm{Se}$, and $\mathrm{As}$ in a shallow, unconsolidated aquifer. Surface water was characterised by its low $\sum$ REE concentration and a depletion of light REE (LREE) relative to medium and heavy REE (MREE and HREE). The deepest groundwater at the site exhibited a caret-shaped REE pattern with MREE enrichment, which was in congruence with local sandstone bedrock. Using LREE:HREE and MREE:HREE ratios, it was found that most surface and groundwater samples shared a common evolutionary pathway which was effectively controlled by depth. A negative sloped REE pattern, unique to a previously unidentified refinery process waste (slag), was found in shallow groundwater from the centre of the refinery site; these waters had a distinctive evolution according to LREE:HREE and MREE:HREE ratios. The Ce anomaly of waters $\left(\mathrm{Ce}-[\mathrm{La}+\mathrm{Pr}]^{0.5}\right)$ was used to identify areas more or less affected by sorption processes, and where reductive dissolution of $\mathrm{Fe} / \mathrm{Mn} \mathrm{OOH's} \mathrm{was}$ occurring. Our results provide an important insight into the source of contaminants into the aquifer as well as the geochemical factors controlling their fate. This is a critical step required prior to forward geochemical modelling. 